\title{
ALTERNATIVAS LATINO-AMERICANAS PARA CRISE AMBIENTAL GESTADAS ALÉM DO CAPITALISMO
}

JeAneth Nunes Stefaniak

Doutora em Direito pela PUC/PR, coordenadora do grupo de pesquisa Direito e Sustentabilidade, professora adjunta da Universidade Estadual de Ponta Grossa - PR.

\section{Resumo}

Este estudo objetiva analisar propostas constantes nas legislaçôes latino-americanas quanto ao tratamento dado ä natureza e que se contrapóe ao modo de produção capitalista, hoje hegemônico, com lógica de reprodução destrutiva, com expansão incessante, produzindo grave crise ambiental onde o planeta encontra-se imerso. A constituição do Equador e a Lei da Mãe Terra da Bolívia, são experiências revolucionárias, pelo formato dado a sustentabilidade, numa complexidade ambiental, tratam a terra como ser vivo de fundamental importância a manutenção da existência humana, recriam a ética de responsabilidade no relacionamento com o meio ambiente. A natureza assim concebida possui direitos tutelados sob o princípio do in dúbio pro meio ambiente, como interesses superiores criando mecanismos que garantam esse modo alternativo de vida, denominado bem viver, distinto do viver melhor das sociedades contemporâneas de orientaçáo capitalista.

\section{Palavras-chave}

Sustentabilidade; Crise ambiental; Bem viver.

\section{Abstract}

This study aims to analyze some proposals contained in the laws Latin American for the treatment of nature and which opposes the capitalist mode of production, currently hegemonic, which have a destructive logic of reproduction, incessant expansion produced serious environmental crisis in which the planet is immersed. The constitution of Ecuador and the Law of Mother Earth in Bolivia, constitute revolutionary experiences in seeking a new format for sustainability, considering the environmental complexity, treats the earth as a living being and fundamental to the maintenance of the human existence, recreating the ethics of responsibility in the relationship with the environment. The nature so conceived has rights that must be protected on the basis of in dúbio pro environment, placing environmental concerns at a higher hierarchical level, besides creating 
several mechanisms to ensure that alternative mode of living, there called good life, which distinguished contemporary societies live better on capitalist liberal guidance.

\section{Key words}

Sustainability; Environmental crisis; Good life.

\section{Introdução}

Apesar da supremacia do projeto econômico capitalista, alguns povos não alinhados a um discurso único, ou na perspectiva de Mészáros $^{1}$, para além do capital revolucionam o debate contemporâneo apresentando um conjunto de ideias que antagonizam com àquelas propostas emanadas no modo de produção atualmente hegemônico. Assim, alternativas que consideram a complexidade da questão ambiental apresentam-se como possibilidades que merecem análise criteriosa, pois, emergem de experiências que estão sendo gestadas escapando do fundamentalismo mercantil e da crença de que o atual estágio da vida humana, sob a ótica da economia representa efetivamente o fim dos tempos. Fundamenta-se ainda na busca de um outro modo de viver e, por uma outra globalizaçáo, conforme concepção teórica de Santos².

Sob um manto ideológico se produz a crença de que o discurso único prevalece e se solidifica de tal modo que nenhuma outra experiência é possível. $\mathrm{O}$ mundo globalizado, conectados, interligados, no mercado global, a homogeneizar econômica, política e socialmente todos os povos, num culto ao individualismo e ao consumo, propagandeiam que o capital é permanente e universal, numa espécie de determinismo desse estilo de vida.

A despeito do avanço sem precedentes dessa formação social, com a presença dos atores hegemônicos em todos os cenários, com ascendência já consumada, e, o capital por se apresentar como um sociometabolismo ${ }^{3}$ incontrolável, este sistema econômico é essencialmente destrutivo em sua lógica. A mercadorização da vida humana, exige uma reproduçáo constante que conduza a expansão ilimitada do sistema produtivo. O limite do capitalismo é, no entanto, o limite da natureza, porque a natureza é um sistema fechado, que não pode se ampliar, e, assim fisicamente se constitui num obstáculo a essa auto reprodução.

1 Mészáros, István. Para além do capital: rumo a uma teoria da transição. São Paulo: Boitempo Editorial, 2009.

2 Santos, Milton. Por uma outra globalização: do pensamento único à consciência universal. $19^{\mathrm{a}} \mathrm{Ed}$. Rio de Janeiro: Record, 2010, p. 18.

3 Marx entende por metabolismo social o processo por meio do qual a sociedade humana transforma a natureza externa e, ao fazê-lo, transforma sua natureza interna. A ação de transformar a natureza externa constitui o processo de trabalho, e seu efeito sobre a natureza interna se manifesta na forma como se estabelecem as relaçôes sociais de produçấo. 
O surgimento de alternativas ao modo de reprodução metabólica do capital é urgente frente a crise estrutural do sistema. Segundo a perspectiva de Santos, pode-se compreender o mundo sob três óticas: um pela forma como nos fazem vê-lo, ao que ele denominada de globalização como fábula, cuja ideal é uniformizar a tudo e a todos no grande mercado global, sempre na perspectiva de perpetuação do capital; o segundo modo, designado de globalização como perversidade, onde o mundo pode ser visto como ele é com toda a sorte dos efeitos maléficos da evolução negativa da humanidade, alastrando-se pelos territórios e finalmente pode-se olhar o mundo como ele pode ser, ou nas exatas palavras desse saudoso professor, uma outra globalização, mais humana, onde o avanço tecnológico e o conhecimento cientifico estariam a serviço de outros objetivos, com fundamento em valores sociais e políticos baseada numa sociodiversidade dos povos, alicerçada no resgate das relaçóes locais.

\section{A Crise Ambiental: $\mathbf{0}$ Colapso da Racionalidade Econômica}

A crise ambiental é fruto das atividades humanas, que ao longo dos dois últimos séculos ignorou o chamado limite ecológico, ou a resiliência do planeta, conforme Veiga5, a possibilidade de um colapso é iminente. A percepção do adensamento da crise está evidenciada em fatores tais como a explosão demográfica, a degradação ambiental e o estabelecimento do debate em torno da necessidade de limitar o crescimento econômico, assim esta crise é global porque o problema ambiental não reconhece barreiras geográficas, se expande além-fronteiras e agride o planeta como um todo ${ }^{4}$.

Questóes envolvendo, por exemplo, o aquecimento global e as mudanças climáticas dele oriundas, são aspectos mais visíveis da proporção da crise ecológica na qual estamos imersos, não sendo, no entanto, a sua única faceta preocupante. $\mathrm{O}$ superaquecimento da terra vem sendo acompanhado pelo IPCC - Painel Intergovernamental de Mudanças Climáticas, que divulga relatórios sobre a temperatura média da Terra que vem aumentando ao longo dos últimos 150 anos.

Apesar da falta de consenso cientifico acerca dessa elevação mais acentuada da temperatura terrestre, as causas antropogênicas, a ação humana, especialmente a atividade industrial6, estão no topo da lista das razóes do aquecimento global. A Terra recebe raios solares e devolve grande parte dessa radiação de calor ao espaço, no entanto os poluentes lançados na atmosfera, chamados de gases de efeito estufa ${ }^{5}$, retêm parte da radiação de

4 Conforme dados do IPCC, grandes quantidades de gases têm sido emitidas para a atmosfera desde que começou a revolução industrial, a partir de 1750 as emissões de dióxido de carbono aumentaram 31\%, metano $151 \%$, óxido de nitrogênio $17 \%$ e ozônio troposférico $36 \%$.

5 Os gases de efeito estufa estáo listados no anexo A do Protocolo de Kyoto, assinado em 1997 e, que entrou em vigor em 16 de fevereiro de 2005, são os seguintes: dióxido de carbono (CO2); metano (CH4); 
calor, causando assim a elevação da temperatura do planeta. Os dados do IPCC ${ }^{6}$ demonstram que ao longo do século $\mathrm{XX}$, a temperatura da terra se elevou em torno de $0,6^{\circ} \mathrm{C}$ e que prognósticos indicam que até o ano de 2100 a temperatura do ar e da superfície terrestre se eleve entre 1,4 a $5,8^{\circ} \mathrm{C}$ se comparado com o ano 1990 e que a média da temperatura do mar se eleve em $0,99^{\circ} \mathrm{C}$ em todo o mundo ${ }^{7}$.

Apesar de muitas vozes se levantarem contra as previsóes consideradas catastróficas, extremistas e que para alguns chegam a ser até fantasiosa ou ficcionista, da possibilidade de destruição do planeta, mesmos estes descrentes, não negam a existência de grandes problemas ambientais, tais como a redução da camada de ozônio, o aquecimento global, causado pela emissão dos gases de efeito estufa, e as transformaçóes que tais fatores veem causando ao meio ambiente, a ameaça é real e global.

Para Lovelock a situação do planeta Terra aproxima-se de um estágio crítico e, suspeita que pouca coisa possa ser feita para evitar o ritmo de destruição, para o qual a humanidade caminha, ou seja, a situação é irreversível, no tocante ao aquecimento global e seus efeitos devastadores sobre todos os modos de vida no planeta.

\section{A Limitação das Propostas Capitalistas para Contenção da Crise Am- biental}

Apesar dos prognósticos sombrios para o futuro da Terra, a história da humanidade, demonstra que nas situaçóes de emergência se buscam alternativas e assim tem ocorrido com a questão ambiental: nas últimas décadas muitas propostas têm sido elaboradas na tentativa de refrear a degradação ecológica. O desenvolvimento sustentável se constituiu numa dessas propostas que buscam conciliar a necessidade de desenvolvimento econômico da sociedade contemporânea, e a proteção ambiental, e por assim ser, o desenvolvimento sustentável, se tornou um paradigma do desenvolvimento, além do desenvolvimento sustentável, em seu complemento emerge ainda o debate sobre a internalização das externalidades positivas e negativas, que equivale a computar os benefícios, quando positiva ou custos ocultos, quando negativa e imputá-los ao seu responsável econômico e conforme Montibeller-Filho ${ }^{8}$, as externalidades ambientais exigem um mercado ecologicamente equilibrado, a grande questão, que será explorada no capítulo três, diz respeito às potencialidades de implementação dessa proposta.

óxido nitroso (N2O), hidrofluorcabonos (HFCs), perfluorcarbonos (PFCs) e hexafluoreto de enxofre (SF6).

6 Intergovernmental Panel on Climate Change. http://www.ipcc.ch/pdf/supporting-materiallexpert-meetingdetection-anthropogenic-2009-09.pdf .

7 Conforme dados constantes em http://www.ipcc.ch/pdf/climate-changes-2001/impact-adaptationvulnerability/impact-spm-ts-sp.pdf.

8 Montibeller-Filho, 2001, O mito do desenvolvimento sustentável: meio ambiente e custos sociais no moderno sistema produtor de mercadorias. Florianópolis: Editora da UFSC, 2001., p. $86 .$. 
Outra possibilidade também de discutível eficácia, são os tributos ecológicos, que se constituiriam em instrumento a serem utilizados pelos Estados, como objetivo de promover a tutela ambiental. Esta opção de política ambiental, já vem sendo utilizada na Europa, que tributa atividades empresariais potencialmente poluidoras, ou por outro lado, as que promovem a proteção ambiental, podem ser beneficiárias de incentivos fiscais, estas medidas em tese permitiriam uma maior conservação ambiental e contribuiriam para um meio ambiente ecologicamente equilibrado. Esta proposta de tributação ambiental, bastante polêmica é viabilidade bastante duvidosa, no que respeita ao escopo de sustentabilidade ambiental.

Estas propostas, entre outras, têm um caráter de complementariedade ao desenvolvimento sustentável, e suas hipóteses de aplicação permitiriam a humanidade prosseguir na caminhada do desenvolvimento, mas de modo harmônico e integrado com o meio ambiente, estas propostas, umas mais que outras ganham foros de unanimidade, porém na mesma medida crescem os posicionamentos críticos no sentido de que são medidas insuficientes ao controle da crise ambiental. Assim, a temática da preservação, assume a cada dia uma importância maior, tanto que no final do século XX e inicio do século XXI, tais propostas passam a permear discursos, programas e projetos políticos. Porém, a dúvida que resta, é se elas são capazes de tirar o planeta Terra e a humanidade da rota de destruição em que se encontram?

O direito ao meio ambiente equilibrado, hodiernamente visto como um direito humano fundamental e de caráter universal, numa perspectiva de que uma nação isoladamente não pode conter o avanço da degradação ecológica, sendo necessárias açóes globais, medidas que envolvam o planeta como um todo, pois a destruição ambiental, na esteira da economia capitalista não encontra barreiras ou obstáculos ao seu avanço.

Apesar dessa percepção de mundo, o discurso da necessidade do crescimento econômico prevalece, e mesmo com toda a ênfase que dê ao aspecto econômico da trajetória da humanidade, com a aceleraçáo do processo produtivo, este náo conseguiu reduzir o quadro de desigualdade social global. Esta constatação evidencia a impotência da racionalidade econômica em oferecer soluçóes para os problemas recorrentes da modernidade mal acabada.

\section{No Equador um Novo Olhar sobre a Natureza}

O Equador em julho de 2008 aprovou sua nova Constituição com grandes inovaçôes, sendo que, alguns dispositivos constitucionais revolucionam o modo de se tratar a natureza, caracterizando a Terra, como ser vivo e a ela destinando direitos, tais como o direito a vida e a garantia da reprodução de seus processos naturais. A Constituição Equatoriana ao transformar a relação com meio ambiente pode vir a se constituir num novo paradigma para legislação ambiental. 
$\mathrm{O}$ artigo $71^{9}$ da norma constitucional trata a natureza, a terra, a qual denomina de Pachamama ${ }^{10}$ como um organismo vivo, por excelência, já que é a partir dela que se reproduz todas as outras formas de vida, supera assim o tratamento da natureza como uma coisa ou um mero bem jurídico, ou ainda na perspectiva capitalista, como uma mercadoria, que pode servir a interesses egoísticos privados, em detrimento do interesse coletivo.

Ao reconhecer direitos à natureza a Constituição adota outro paradigma para o desenvolvimento social e econômico, preconizando uma economia social e solidária, que envolverá especialmente setores cooperativistas, associativos e comunitários, de modo a distribuir melhor o resultado do processo produtivo, além de estimular o consumo responsável. Do ponto de vista axiológico, a intenção do legislador é promover o ideal comunitário, gestando-se inclusive um novo formato de propriedade, nem pública nem privada, mas comunitária, em detrimento do individualismo e dos interesses privados.

Nesta linha de raciocínio a lei maior do Equador quer se constituir num novo pacto social, numa relação intercultural, resgatando e reconhecendo oficialmente as línguas ancestrais quechua e shuar, que a partir da norma constitucional estão incorporados como idiomas oficiais do país.

Além do artigo 71, a Constituição Equatoriana, traz em seu titulo VII a adoção dos princípios da doutrina do bem viver ${ }^{11}$, que se constitui na promoção de uma forma distinta de relacionar-se com outros seres humanos e com a natureza profundamente diferente do modo de existir dos países capitalistas centrais. A ideia principal é resgatar valores históricos e culturais dos povos andinos ${ }^{12}$. Opóe-se a ideologia da acumulaçáo desmedida e desnecessária que aniquila tudo que aparece como obstáculo à sua expansão. $\mathrm{O}$ bem viver antagoniza com o viver melhor, da cultura capitalista, porque este busca o crescimento contínuo, através do produtivismo, para que poucos possam ter uma vida melhor, em detrimento da maioria.

A base da proposta do bem viver é a retomada do modo de vida dos ancestrais dos povos andinos, determina uma transformação radical no relacionamento com a natureza,

9 Art. 71.- La naturaleza o Pachamama, donde se reproduce y realiza la vida, tiene derecho a que se respete integralmente su existencia y El mantenimiento y regeneración de sus ciclos vitales, estructura, funciones y procesos evolutivos.

10 Marés, Carlos Frederico. A funçáo social da terra. Porto Alegre: Fabris Editor, 2003. Esclarece que diversas culturas consideram a Terra uma divindade e lhe dedicam tributo. Algumas a denominam de pai, pátria e outras de máe, Pacha Mama, que é como os quéchuas a chamam porque a representam na forma de uma mulher que traz ao colo uma criança.

11 O bem viver constitui-se numa política de sociedade sustentável, não sob a ótica da economia, mas do equilíbrio de todas as formas de vida, onde o que interessa é a manutenção de todos os ciclos de vida, não só a vida humana, estas propostas envolvem a comunidade como um todo, como guardiães do patrimônio natural.

12 Cultura oriunda dos índios que compóem a América Andina, formada pelos países da América do sul, atravessados pela Cordilheira dos Andes: Chile, Bolívia, Peru, Equador, Colômbia e Venezuela. 
dada a importância que esta assume para esta formação cultural. A natureza como organismo vivo e fonte de toda vida, deve ser respeitada em sua amplitude e complexidade e, assim a Constituição do Equador regula a diversidade e recursos ambientais através do reconhecimento de princípios ambientais estabelecidos em seu artigo $395^{13}$, objetivando o compromisso comunitário na defesa da natureza, fazendo prevalecer os direitos ambientais, sempre que pairar dúvidas acerca da aplicação dessas normas, numa perspectiva do in dubio pro natureza, com aplicação efetiva, colocando a natureza do ponto de vista hierárquico, no ápice da pirâmide e, em especial quando houver colisão de interesses.

Além da busca do pacto comunitário em favor da natureza, a Constituição Equatoriana preconiza sançóes severas contra as agressóes ao meio ambiente, caracterizando estes atos delituosos contra o meio ambiente, como imprescritíveis, permitindo assim a punição de crimes ambientais a qualquer tempo.

Em outros dispositivos constitucionais se observa a preocupação com a soberania nacional, quando a constituição veda expressamente a aquisição de propriedade por estrangeiros em áreas de segurança nacional ou de proteção ambiental ${ }^{14}$.

Um ideal do bem viver está presente ainda em outros artigos que preconizam a política voltada para a arborização, reflorestamento e o resgate do solo, com incentivo a agricultura, contrárias a monocultura e ao uso de biotecnologias experimentais que possam colocar em risco o equilíbrio ambiental. Seu uso deve ser fortemente controlado pelo Estado.

A questão dos recursos hídricos aparece com veemência no texto constitucional, com vedação a possibilidade de privatização e às atividades que possam afetar a qualidade da água, priorizando a manutenção de ecossistemas e consumo humano racional, em detrimento de atividades econômicas ${ }^{15}$. As alterações climáticas também foram objeto de regulamentação constitucional, em que o legislador constituinte estabeleceu a necessidade de açóes concretas do Estado voltadas para a redução de emissóes de gases de efeito estufa, independentemente de outros compromissos internacionais.

13 Art. 395.- La Constitución reconoce los siguientes principios ambientales:

1. El Estado garantizará un modelo sustentable de desarrollo, ambientalmente equilibrado y respetuoso de la diversidad cultural, que conserve la biodiversidad y la capacidad de regeneración natural de los ecosistemas, y asegure la satisfacción de las necesidades de las generaciones presentes y futuras.

2. Las politicas de gestión ambiental se aplicarán de manera transversal y serán de obligatorio cumplimiento por parte del Estado en todos sus niveles y por todas las personas naturales o jurídicas en el territorio nacional. 3. El Estado garantizará la participación activa y permanente de las personas, comunidades, pueblos y nacionalidades afectadas, en la planificación, ejecución y control de toda actividad que genere impactos ambientales.

4. En caso de duda sobre el alcance de las disposiciones legales en materia ambiental, éstas se aplicarán en el sentido más favorable a la protección de la naturaleza.

14 Art. 395 da Constituiçáo.

15 Art. 411 da Constituição. 
Em consonância com esta nova visão ambiental, o meio ambiente artificial deve transformar-se para complementar os direitos da natureza, especialmente no tocante aos meios de transportes, com incentivo a utilização de ciclovias e outros meios não motorizados. A criação de mais áreas verdes para lazer da populaçáo deve ser priorizada, num resgate de valores do bem viver.

A Constituição do Equador se reveste de fundamental importância quando lança um olhar para natureza como um organismo vivo que é, e ao assim tratá-la, determina que o relacionamento humano com o meio ambiente deverá sofrer profundas transformaçóes. A natureza por esta ótica não pode ser considerada uma mercadoria, pois representa a essência da vida. A Constituição Equatoriana inova e pode se constituir num novo paradigma para a humanidade, para a construção de uma sociedade ecológica em toda a sua complexidade.

\section{Na Bolívia uma Lei a Favor da Mãe Terra}

A Bolívia ${ }^{16}$ revoluciona o debate acerca da questão ambiental, aprovando a denominada Lei da Mãe Terra, onde estabelece diversos direitos à natureza, que tem como foco a transformação da relação humana com a natureza, buscando-se estabelecer uma relação orgânica, que procure ver e tratar a natureza de modo diferenciado daquele que o sistema capitalista historicamente estabeleceu, agredindo e explorando-a e produzindo a grave crise ambiental onde a humanidade encontra-se imersa.

A lei aprovada originalmente trazia 11 artigos que engloba especialmente esse relacionamento homem e natureza, tendo como pressuposto a ideia de que a natureza não precisa do ser humano para viver, já o homem não pode sobreviver sem a natureza.

Os direitos estabelecidos em favor da Mãe Terra são os seguintes: direito à vida, o direito da continuação de ciclos e processos vitais livres de interferência humana, o direito a água e ar limpos, o direito ao equilíbrio, e o direito de não ter estruturas celulares modificadas ou alteradas geneticamente. Ela também vai assegurar o direito da Nação de não ser afetada por grandes estruturas e projetos de desenvolvimento que afetem o equilíbrio de ecossistemas e das comunidades locais, além de condenar o consumismo indiscriminado criado pela sociedade capitalista, por se constituir no maior inimigo do meio ambiente.

Os defensores da lei da Mãe Terra declaram que esta lei significa o ressurgimento da cultura indígena andina que coloca a Terra e o meio ambiente no centro da vida, e por se

16 Em meio a uma profunda reestruturação do sistema legal boliviano, como reflexo da mudança constitucional que o país aprovou em 2009, está em tramitaçâo no Legislativo do país a proposta de se aprovar um conjunto de leis para garantir os direitos da Mãe-Terra. A proposta é equiparar o meio ambiente aos seres humanos, numa espécie de extensão da Declaração Universal dos Direitos Humanos aos animais, plantas etc. Com isto, o governo do presidente Evo Morales diz acreditar que o país fará uma revolucionária mudança na história da Humanidade. 
constituírem no eixo central de onde emana toda a vida, esta deve possuir direitos específicos que agora se encontram positivados na lei.

A lei da Mãe Terra se baseia igualmente nos princípios do bem viver que basicamente se opôe ao viver melhor, com valores voltados para um modelo de vida mais ecológico, com resgate da história, vestimenta, alimentação, idioma dos povos andinos que valorizavam especialmente os bens naturais.

A essência da proposta da nova lei a favor da Máe Terra é a de retomar conceitos ancestrais tais como a vida em comunidade, o respeito a mulher e aos outros, a sabedoria oriunda da experiência, priorizar a complementariedade entre os seres vivos, distribuindo racionalmente os recursos naturais, especialmente a água, combinar os alimentos conforme as estaçóes do ano, reincorporar a agricultura à vida das comunidades, enfim uma sociedade distinta sem exclusão, reconhecendo mais que direitos humanos, direitos cós$\operatorname{micos}{ }^{17}$.

A lei da Mãe Terra, com fundamentos éticos, tem como característica a persecução dos seguintes valores: priorizar a vida, em todas as suas formas, harmonizando-as para que existam equilibradamente; $\mathrm{O}$ respeito a diferença, sem qualquer tipo de discriminação ou submissão, a todos povos e culturas; A valorização cultural, pressupóe o respeito aos costumes e a experiência dos ancestrais; Distribuição equitativa dos recursos naturais, condenando-se a acumulação de riquezas em mãos de poucos. A questão da água assume grande relevância, neste debate, por se constituir num recurso natural finito e de grande importância para todas as formas de vida; $\mathrm{O}$ equilíbrio com a natureza não pressupóe somente o viver bem em comunidade, pois exclui outras formas de vida, assim o que se deve garantir é a harmonia dos seres vivos; Saber comer, a importância da alimentaçáo para os seres humanos é vital, e encontram-se desvirtuada em prol de uma cultura globalizada, desrespeitando o ciclo natural de produção de alimentos, num mundo globalizado se impóe o consumo da moda, de fast foods, ignorando hábitos ancestrais; inclui ainda o saber beber e saber dançar, saber trabalhar, numa referência clara ao resgate cultural; Retomar o abya ayala, que equivale a reconstituição do ideal da formação comunitária entre os povos, com base na solidariedade; A vida em comunidade, nessa perspectiva do bem viver, exige a superação da democracia liberal, mesmo num viés de democracia participativa, mas numa outra dimensão de compromisso coletivo com os destinos de todos; Finalmente a recuperação dos recursos naturais degradados, restabelecendo o equilíbrio

17 Discorre David Choquehuanca, ministro das Relaçóes Exteriores da Bolívia e especialista em cosmovisão que: "Para os que pertencem à cultura da vida, o mais importante não é o dinheiro nem o ouro, nem o ser humano, porque ele está em último lugar. O mais importante são os rios, o ar, as montanhas, as estrelas, as formigas, as borboletas (...) O ser humano está em último lugar, para nós o mais importante é a vida”, in: http://planetasustentavel.abril.com.br/blog/planetaurgente/bolivia-cria-lei-mae-terra-287125_post.shtml, consulta em 29.09.2011. 
do meio ambiente, opondo-se a utilização irracional dos recursos ambientais; fortalecimento da soberania na defesa dos bens naturais ante à expansão das grandes corporaçóes.

Observa-se que os valores constantes na elaboração da Lei da Mãe Terra, preconizam o rompimento com o modo de viver capitalista, porque esta náo vislumbra a satisfaçáo direta de necessidades humanas, almeja tão somente o lucro. Esta lei pode vir a estabelecer obstáculos à expansão capitalista e a homogeneização da economia, da política, da ética e da cultura.

A aplicação da lei depende ainda do estabelecimento de representantes que manejem os direitos nela previstos, assim, dispóe sobre a criação de uma defensoria da Mãe Terra, cujas atribuiçôes serão definidas por lei complementar, mas que objetivamente tutelará a natureza em toda a extensão dos direitos estabelecidos em favor desta, em especial com a finalidade de permitir a regeneração da natureza degradada pelos longos períodos de exploração, e finalmente, para possuir eficácia, a lei veda a mercantilização e a monetarização dos bens ambientais.

Tanto a Constituição do Equador como a lei a favor da Mãe Terra da Bolívia, possuem características comuns no sentido de resgatar a diversidade cultural, fundamental para realizar o enfrentamento à crise ambiental. Segundo Foladori ${ }^{18}$ a perda da diversidade cultural é uma das importantes dimensóes da crise ecológica, porque o capitalismo necessita destruir todas as formas de produção para atender a sua necessidade expansionista, para impor mercado para suas mercadorias produzidas, além de amoldar a força de trabalho de minorias étnicas dentro das necessidades do processo produtivo. Assim, a homogeneidade cultural tem sido a marca da sociedade industrial capitalista.

As alternativas, Equatoriana e Boliviana podem vir a se constituir em um novo paradigma a transformar o relacionamento do ser humano com a natureza, se revestindo já de grande importância porque permite lançar um novo olhar sobre a natureza, como organismo vivo que é, superando sua mercadorização imposta pelo capitalismo, o que efetivamente coloca a questão ambiental num outra esfera de reflexão, escapando do debate estreito e perverso da lógica do capital.

\section{Conclusões}

A constatação de que a lógica produtivista e mercantil da civilização capitalista industrial conduz a humanidade a um colapso ecológico é evidente e objetivamente detectável a partir dos sucessivos desastres ecológicos ocorridos nas últimas décadas. O sistema capitalista não consegue ler outro signo a não ser o da sua reprodução em busca do lucro,

18 Foladori, Guillermo. Limites do Desenvolvimento Sustentável. Tradução Marise Manuel. Campinas: Editora da Unicamp, 2001, p. 189. 
mesmo que para atingir seus objetivos seja necessário destruir as condiçóes próprias de existência. A natureza por sua vez possui recursos que não se submetem a à lógica e aos ciclos econômicos.

A dominação da natureza impóe-se inicialmente como necessidade de sobrevivência humana e termina por se constituir na grande ameaça a continuidade da vida humana no planeta. Os recursos naturais degradados ao longo dos séculos de exploração intensa pelas forças produtivas correm o risco de se extinguirem. Assim o capitalismo destrói efetivamente as próprias condições, e coloca em risco a manutenção de todas as formas de vida no planeta.

O movimento ecologista ocupa papel de fundamental importância para o avanço da conscientização da questão ambiental, denunciando a gravidade da crise ambiental e os riscos de um colapso iminente. No entanto, os ecologistas, mesmo as correntes que se autodenominam críticas padecem de limitações nas análises acerca do principal causador dos problemas que ameaçam o planeta, que é o modo de produção e consumo da sociedade capitalista. Além do diagnóstico restrito, pecam no que tange as soluçóes propostas para a busca de soluçóes para superar o avanço da destruição do meio ambiente. Todas as soluçóes desde a busca de um desenvolvimento sustentável, a criação de mercados para bens e serviços ambientais e a criação de tributos ecológicos, todos sem exceção buscam alternativas dentro do capitalismo, sem conseguir olhar para além do capital, mesmo numa visão crítica, e o que se pode chamar de crítica possível ${ }^{19}$.

James O'Connor ${ }^{20}$ nesta linha de raciocínio esclarece que a sustentabilidade é uma questão ideológica e política, antes mesmo de ser um problema ecológico e econômico, acentuando o caráter ambíguo do desenvolvimento sustentável e a da impossibilidade de se universalizar tais formas de desenvolvimento econômico.

A ineficácia das propostas capitalistas para superar a crise ambiental resulta no surgimento de um pensamento que vai além da crítica possível formulada no contexto do mundo capitalista, são os chamados ecossocialistas, que conforme Lôwi ${ }^{21}$ trata-se de uma corrente de pensamento e de ação ecológica que faz suas aquisições fundamentais no

19 Lôwy, Michael. Ecologia e Socialismo. São Paulo: Cortez, 2005, p. 46: "O problema é que as propostas feitas pelas correntes dominantes da ecologia política européia são muito insuficientes ou levam a becos sem saída. A sua principal fraqueza é ignorar a conexão necessária entre o produtivismo e o capitalismo, o que leva à ilusáo do 'capitalismo limpo' ou de reformas capazes de controlar os excessos (como, por exemplo, as eco-taxas). (...) Os ecologistas se enganam se pensam que podem fazer a economia da crítica marxiana do capitalismo: uma ecologia que não se dá conta da relação entre 'produtivismo' e lógica do lucro está fadada ao fracasso - ou pior, à recuperação pelo sistema”.

20 Sociólogo, Economista y Professor de Sociologia e Economia na Universidade da Califórnia. Editor da revista "Capitalism, nature, socialism”. In: ¿Es posible el capitalismo sostenible?, p. 4. http://www.iade.org. ar/uploads/c87bbfe5-a8b1-62cf.pdf, consulta em 03.10.2011.

21 Idem, p. 47. 
marxismo, superando a visão estritamente produtivista que pode impedir a construção de uma teoria e prática que efetivamente olhasse de modo crítico tanto a lógica do mercado e do lucro, como o autoritarismo burocrático da experiência do denominado socialismo real, que se mostraram totalmente incompatíveis com a preservação ambiental.

A constatação de que o modo de produção e de consumo dos países capitalista avançados, conduzem a um esgotamento dos recursos naturais e expóe os ecossistemas a toda sorte de poluente. Assim sendo, as condiçôes de vida propiciadas pelo sistema capitalista não podem e não devem ser globalizadas, sob pena da antecipação do colapso ecológico e, mesmo porque, o sistema capitalista se alimenta da manutenção da desigualdade existente entre as naçóes desenvolvidas e as subdesenvolvidas ou em desenvolvimento. Em segundo lugar, a impossibilidade da perpetuidade da expansão capitalista é flagrante e ameaça a sobrevivência da espécie humana.

Assim, não há como construir uma racionalidade ecológica em se mantendo a racionalidade mercantil-industrial, pois estas são antagônicas ${ }^{22}$. As propostas para frear a crise ambiental no âmbito do sistema capitalista são mitos ou fábulas, desprovidas de qualquer efeito prático. Mesmos as açóes em andamento oriundas de medidas que se autodenominam ecologicamente corretas, ou de economia verde, não possuem qualquer eficácia dentro da magnitude da crise ambiental.

As crises no sistema capitalista são cíclicas e em regra são gerenciadas pelo Estado, que desde o advento da modernidade, ocupa papel central, ocorre, no entanto, que as condiçóes gerais desse modo de produção conduzem a crises cada vez mais acentuadas, atingindo limites insustentáveis, como no caso ambiental, onde a ação regulatória do Estado se torna impotente.

A solução para a crise ambiental encontra-se claramente na reorganização do modo de produção e consumo, estabelecida a partir das necessidades reais da população e em consonância com a preservação ecológica, ou seja, com base em critérios não ligados às leis do mercado capitalista ou ainda por um comitê burocrático que determine interesses ou objetivos.

Essa transformação da humanidade exige uma economia de transição com controle total do mercado e com o estabelecimento de um novo modelo de produção. Para o que

22 Montibeller-Filho, Gilberto. O mito do desenvolvimento sustentável: Meio ambiente e custos sociais no moderno sistema produtor de mercadorias. Florianópolis: Ed. Da UFSC, 2001, p. 184: "A relação capital-natureza apresenta tendência de ser cada vez mais antagônica nos sucessivos estágios do capitalismo - mercantilismo; capitalismo industrial-liberal e concorrencial; monopolista; e monopolista transnacional. A ética interna do capitalismo é a conquista da natureza, em nome da necessidade do desenvolvimento, este visto como aumento da produção. No capitalismo expandido, a ética e a da dominação da natureza, no sentido de subjugá-la ao capital". 
Lôwi ${ }^{23}$ denomina de uma nova civilização, para além do reino do dinheiro, subvertendo hábitos de consumo artificialmente induzidos pela publicidade e da produção ao infinito de mercadorias nocivas ao meio ambiente, exemplificando com a necessidade criada pelo mercado mundial, de que cada pessoa deva ter seu carro individual.

Em síntese, Lôwi ${ }^{24}$ ao elencar as bases para a construção de uma sociedade ecossocialista, esclarece que estas propostas, por se fundamentarem em uma nova ética, podem se constituir em pontos de convergência entre movimentos sociais emancipatórios, que em regra atuam em frentes ligadas a lutas especificas, em torno de interesses de classe ${ }^{25}$ para os quais foram criados.

Modificar padrốes de consumo exige uma revolução no modo de vida da humanidade, envolvidos e comprometidos com uma sociedade que tenha por finalidade viver bem e em harmonia com a natureza, delineando-se um novo estilo de vida. Lef ${ }^{26}$ trabalha a categoria do resgate da soberania dos povos em detrimento da soberania do consumidor instalada pela globalização econômica. Essa soberania dos povos exige resgate de processos históricos e culturais para estabelecer regras de coesão e solidariedade social que definirão necessidades e desejos dentro de organizaçóes culturais diferenciadas. Só assim se pode reverter a lógica homogeneizante do mercado globalizado.

A busca de um novo modelo de produção, a revolução nos hábitos de consumo, aliados ao estabelecimento de alternativas energéticas baseados em recursos naturais renováveis ${ }^{27}$, economicamente de custo mais elevado, porém ambientalmente necessárias, a

23 Lowi, 2005, p. 53

24 Idem, 2005, p. 61: “- a promoção de transportes públicos - trens, metrôs, ônibus, bondes - baratos ou gratuitos como alternativas para o abafamento e a poluiçáo das cidades e dos campos pelo carro individual e pelo sistema de transportes rodoviários;

- a luta contra o sistema da dívida e os 'ajustes' ultraliberais impostos pelo FMI e pelo Banco Mundial aos países do Sul, com consequências sociais e ecológicas dramáticas: desemprego em massa, destruição das proteçóes sociais e das culturas de víveres, destruiçáo dos recursos naturais para a exportaçáo;

- defesa da saúde pública, contra a poluição do ar, da água (lençóis freáticos) ou dos alimentos pela avidez das grandes empresas capitalistas;

- a redução do tempo de trabalho como resposta ao desemprego e como visáo da sociedade que privilegie o tempo livre em relação à acumulação de bens".

25 Resgatamos aqui noção conceitual de movimento social que norteou a organizaçáo de trabalho anterior de que "os movimentos sociais são traduzidos na ação transformadora de grupos pertencente a uma determinada classe social que se organizam, com interesses mais ou menos homogêneos e tendo por objetivo a construção de uma nova realidade, que produzem a evolução de uma sociedade". Stefaniak, Jeaneth Nunes. Propriedade e função social: perspectivas do ordenamento jurídico e do MST. Ponta Grossa: UEPG, 2003, p. 90.

26 Lef, Enrique. Racionalidade ambiental: a reapropriaçáo social da natureza. Rio de Janeiro: Civilização Brasileira: 2006, p. 236.

27 Lôwi, p. 55, "A revolução energética, a substituição das energias não-renováveis e responsáveis pela poluição e envenenamento do meio ambiente - carvão, petróleo e combustíveis nucleares - por energias ‘leves' e renováveis: água, vento, sol”. 
rearticulação do setor de transporte, tendo como critérios as necessidades sociais e ecológicas, se constituindo em medidas restritivas para o uso de veículos indiscriminadamente pela população, considerando a construção ideológica da importância do carro individual na sociedade de consumo. A vida contemporânea está intransitável, pelo número de veículos em circulação, pelos acidentes cada vez mais comuns e pelo ar irrespirável das cidades capitalistas.

Além dos problemas enfocados na organização da economia, fica o alerta de Foster ${ }^{28}$, de que os socialistas ambientais devem se preocupar com uma questão muito maior que é o destino da terra e das suas espécies, pensando a ecologia como uma teoria mais ampla, como processo de mudança envolvendo contingência e co-evolução para entender a complexidade das necessidades humanas e da sustentabilidade do planeta.

As propostas para além do capital tais como, por exemplo, aquelas baseadas nos ideais do bem viver, devem estar atentas para a perspectiva do conteúdo da propriedade privada individual, dos meios de produção, que se mostraram absurdamente antiecológica e a sua manutenção impede qualquer possibilidade da construção de uma sociedade ambientalmente equilibrada. As leis equatoriana e boliviana, já dispóem de uma ideia preliminar do resgate de uma propriedade comunitária, associativista ou na forma cooperativa, nos moldes das organizaçóes de seus ancestrais, que pode se constituir num primeiro passo para a efetiva transformação desse instituto jurídico.

Analisando o arcabouço teórico das propostas que desejam superar a visão capitalista para realizar o enfrentamento efetivo da crise ecológica, se pode concluir que superar o modo de produção de mercadorias, sob a ótica do produtivismo ilimitado e com finalidade exclusiva de obtenção de lucro é mais que um caminho a ser seguido, pois já se constitui numa necessidade para a humanidade e para o planeta, saírem da rota do colapso iminente. Se há caminho alternativo? Os povos indígenas andinos podem mostrar alguns.

\section{Referências}

AMARAL, Paulo Henrique. Direito Tributário Ambiental. São Paulo: Editora Revista dos Tribunais, 2007.

ANTUNES, Ricardo. Apresentando o livro de Mészáros, István. A crise estrutural do capital. 2. ed. ver. e ampliada. São Paulo: Boitempo, 2011.

ASSIN, Mário Luis. VASELY, Fernando Farias. Ambientes glaciais. Disponível em: http://www.geologia.ufpr.br/graduacao/deposicionais/ambientesglaciais.pdf. Acesso em 10 ago 2011.

28 Foster, John Bellamy. A ecologia de Marx: materialismo e natureza. 2a Ed. Rio de Janeiro: Civilizaçấo Brasileira, 2010, p. 347. 
BARRAL, Welber; FERREIRA, Gustavo Assed. Direito Ambiental e desenvolvimento. In: BARRAL, Weber; PIMENTEL, Luiz Otavio (Orgs.). Direito Ambiental e Desenvolvimento. Florianópolis: Fundação Boiteux, 2006.

BECK, Ulrich. A reinvenção da política: rumo a uma teoria da modernização reflexiva. In: BECK, Ulrich; GIDDENS, Antony; LADH, Scott. Modernizaçáo Reflexiva: política, tradição e estética na ordem social moderna. São Paulo: Editora da Universidade Estadual Paulista, 1997.

BESSA, Paulo, apresentando a obra de PASUKANIS, E.B. A Teoria Geral do Direito e o Marxismo. Rio de Janeiro: Renovar, 1989.

BOBBIO, Norberto. Teoria Geral da política: A Filosofia e as Liçôes Clássicas. Rio de Janeiro: Campus, 2000.

. Liberalismo e Democracia. São Paulo: Brasiliense, 2007.

BOFF, Leonardo. A opção terra: a solução para a terra não cai do céu. Rio de Janeiro: Record, 2009.

CAMARGO, Ana Luiza de Brasil. Desenvolvimento Sustentável - dimensóes e desafios. Rio de Janeiro: Papirus, 2003.

CHOQUEHUANCA, David. Disponível em: http://planetasustentavel.abril.com.br/ blog/ planetaurgente/bolivia-cria-lei-mae-terra- 287125_post.shtml. Acesso em: 29/09/2011.

COASE, Ronald. The problem of social coast. Disponível em: http://www.ordemlivre. org/node/293. Acesso em: 02/09/ 2011.

COSTA, Lucia Cortes. Os impasses do Estado Capitalista: uma análise sobre a reforma do Estado no Brasil. Ponta Grossa: UEPG; Cortez, 2006.

DALY, Herman. A economia é um subsistema do ecossistema. Entrevista ao Instituto Humanitas Unisinos, da Universidade do Vale do Rio dos Sinos, de São Leopoldo - RS, em 15.08.2011.

DEMO, Pedro. Introdução à Metodologia da Ciência. São Paulo: Atlas, 1987.

DERANI, Cristiane. Direito Ambiental Econômico. São Paulo: Max Limonad, 2001.

ENGELS, Friedrich. A origem da família, da propriedade privada e do Estado. Rio de Janeiro: Civilização Brasileira, 1981.

. Situação da Classe Trabalhadora na Inglaterra. Tradução de Rosa Camargo Artigas e Reginaldo Forti. São Paulo: Global, 1985.

FIORILlO, Celso Antonio Pacheco. Curso de Direito Ambiental. São Paulo: Saraiva, 2011. 
FOLADORI, Guillermo. Limites do Desenvolvimento Sustentável. Tradução de Marise Manuel. Campinas: Editora da Unicamp, 2001.

FOSTER, John Bellamy. A ecologia de Marx: materialismo e natureza. 2.ed.. Rio de Janeiro: Civilização Brasileira, 2010.

FURTADO, Celso. O mito do desenvolvimento econômico. Rio de Janeiro: Paz e Terra, 1974.

GALEANO, Eduardo. Quatro mentiras sobre o meio ambiente. Disponível em: http:// ponto.outraspalavras.net/2011/05/17/eduardo-galeano-aponta-quatro-mentiras-sobre-ambiente/. Acesso em: 13/09/2011.

GARCIA, Edmundo et al. Água - esperança e futuro. Disponível em: http://books. google.com.br/books. Acesso em 02 set 2011.

GOIS, Antônio. Muvuca Planetária: Em outubro seremos 7 bilhóes. Folha de São Paulo, Caderno Ilustríssima, p. 4, 14 ago. 2011.

. Agora somos 7 bilhóes. Folha de Sáo Paulo, Caderno Mundo, p. A26, 30 out. 2001, B.

GROSSI, Paolo. História da propriedade e outros ensaios. Tradução de Luiz Ernani Fritoli e Ricardo Marcelo Fonseca. Rio de Janeiro: Renovar, 2006.

HABERMAS, Jurgen. A crise de legitimaçáo no capitalismo tardio. Rio de Janeiro: Tempo Brasileiro, 1999.

HARDIN, Garret. Tragedy of the communs. Disponível em: http://www.garretthardinsociety.org/.../art_tragedy_of_the_communs. Acesso em: 04 set 2011.

HARVEY, David. A produçáo capitalista no espaço. São Paulo: Annablume, 2005.

HAYEK, Friedrich A. Os fundamentos da Liberdade. São Paulo: Visão, 1983.

HOBSBAWN, Eric J. A era do Capital: 1848 - 1875. Rio de Janeiro: Paz e Terra, 1996.

. A era dos extremos: o breve século XX: 1914 - 1991. São Paulo: Companhia da Letras, 1995.

. O novo século: entrevista a Antonio Polito. São Paulo: Companhia das Letras, 2000 .

INTERGOVERNMENTAL Panel on Climate Change. Disponível em: http://www.ipcc. $\mathrm{ch} / \mathrm{pdf} /$ supporting-material/expert-meeting-detection-anthropogenic-2009-09.pdf. Acesso em: 09/09/2011.

LEFF, Henrique. Racionalidade Ambiental: a reapropriaçáo social da natureza. Rio de Janeiro: Civilização Brasileira, 2006. 
. Saber ambiental: sustentabilidade, racionalidade, complexidade e Poder. 3.ed.. Petrópolis: Vozes, 2001.

LEFEBVRE, Henri. A revoluçáo urbana. Belo Horizonte: Editora UFMG, 1999.

LOCKE, John. Segundo Tratado sobre o Governo. Texto integral. São Paulo: Martin Claret, 2002.

LOWI, Michael. Ecologia e socialismo. São Paulo: Cortez, 2005.

LOVELOCK, James. A vingança de gaia. Rio de Janeiro: Intrínseca, 2006.

LUKÁCS, Gyorgy. Ontologia do ser social: os princípios ontológicos fundamentais de Marx. 1999.

MACHADO, Paulo Afonso Lemes. Direito Ambiental Brasileiro. 9.ed.. São Paulo: Malheiros, 2001.

MARÉS, Carlos Frederico. A funçáo social da terra. Porto Alegre: Fabris Editor, 2003.

MARX, KARL. O Capital: edição popular. São Paulo: Martins Fontes, 1979.

O Capital: Crítica da economia política. Livro 1. Rio de Janeiro: Civilização Brasileira, 2011.

MEIRELES, Henrique da Silva Seixas. Marx e o Direito: para a crítica histórica do paradigma civilístico. Coimbra: Faculdade de Direito da Universidade de Coimbra, 1990.

MELO, João Alfredo Telles. Direito Ambiental, luta social e ecossocialismo. Fortaleza: Edições Demócrito Rocha, 2010.

MÉSZÁROS, István. A crise estrutural do capital. 2.ed.. rev. e ampl. São Paulo: Boitempo, 2011.

Atualidade histórica da ofensiva socialista. São Paulo: Boitempo, 2010.

. Para além do Capital: rumo a uma teoria da transição. Tradução de Paulo Cezar Castanheira e Sergio Lessa. São Paulo: Boitempo Editorial, 2009.

MIAILLE, Michel. Introdução Critica ao Direito. Lisboa: Editorial Estampa, 2000.

MONTIBELLER-FILHO, Gilberto. O mito do desenvolvimento sustentável: meio ambiente e custos sociais no moderno sistema produtor de mercadorias. Florianópolis: Editora da UFSC, 2001.

O'CONNOR, James. ¿Es posible el capitalismo sostenible? In: Capitalism, nature, socialism” p. 4. Disponível em: http://www.iade.org.ar/uploads/c87bbfe5-a8b1-62cf. pdf. Acesso em: 03/10/2011. 
OMM. PNUMA. Tercer informe de evaluación: Cambio climático 2001. Impactos, adaptación y vulnerabilidad. Resumen para responsables de políticas y Resumen técnico. Disponível em: http://www.ipcc.ch/pdf/climate-changes-2001/impact-adaptation-vulnerability/ impact-spm-ts-sp.pdf. Acesso em 15 set 2011.

ONU. Acuerdos de Cancun. Disponível em: http://unfccc.int/meetings/cop_16/.php. Acesso em 04 set 2011.

OTT, Konrad. The case for strong sustainability. In: OTT, Konrad; THAPA, Phillipp (Eds.). Greifswald's Environmental Ethics. Greifswald: Steinbecker Verlag Ulrich Rose, 2003.

PÁDUA, Susana Machado. Afinal, qual a diferença entre Conservaçáo ou Preservaçáo? Disponível em: www.oeco.com.br. Acesso em: 26/07/2011.

PASUKANIS, Eugeny Bronislanovich B. A teoria geral do Direito e o marxismo. Rio de Janeiro: Renovar, 1989.

PERRET, Bernand. O capitalismo é sustentável? São Paulo: Edições Loyola, 2011.

POLANYI, Karl. A grande transformaçáo: as origens de nossa época. Rio de Janeiro: Campus, 1980.

RELATÓRIO Brundtland. Disponível em: www.scribd.com/Relatorio-BrundtlandNosso-Futuro-Comum-Em-Português. Acesso em: 09/08/2011.

SACHS, Ignacy. Caminhos para o desenvolvimento sustentável. Rio de Janeiro: Garamond, 2009.

. Desenvolvimento: includente, sustentável, sustentado. Rio de Janeiro: Garamond, 2008.

SANTOS, Milton. Por uma outra globalizaçáo: do pensamento único á consciência universal. 19.ed.. Rio de Janeiro: Record, 2010.

SEN, Amartyia. Desenvolvimento como liberdade. São Paulo: Companhia das Letras, 2000.

SERRES, Michel. O contrato natural. Rio de Janeiro: Nova Fronteira, 1991.

STEFANIAK, Jeaneth Nunes. Propriedade e funçáo social: perspectivas do ordenamento jurídico e do MST. Ponta Grossa: Editora UEPG, 2003.

STEFANIAK, João Luiz. Entre a Miragem e a Utopia: A Efetividade do Direito Humano e Fundamental à Moradia na Cidade Capitalista. Dissertação (Mestrado) _ Mestrado em Ciências Sociais Aplicadas, Universidade Estadual de Ponta Grossa, 2011.

STEFANO, José Caetano da Silveira. Externalidades negativas: as abordagens neoclássica e institucionalista. Revista FAE, Curitiba, v. 9, jul/dez, 2006. 
SOUZA, Marcelo Lopes. A prisão e a Ágora: reflexôes em torno da Democratização do Planejamento e da Gestão das Cidades. Rio de Janeiro: Bertrand Brasil, 2006.

TERRA DE DIREITOS. Pagamento por serviços ambientais e flexibilizaçáo do código florestal para um capitalismo "verde”. Disponível em: http://terradedireitos. org.br/wp-content/uploads/2011/08/Analise-PSA-CODIGO-Florestal-e-TEEB-_ Terra-de-direitos.pdf. Acesso em 02 set 2011.

TIGAR, Michel e; LEVY, Madeleine R. O direito e a Ascensáo do Capitalismo. Rio de Janeiro: Zahar Editores, 1978.

VEIGA, José Eli. A emergência socioambiental. São Paulo: Editora Senac, 2007.

. Desenvolvimento sustentável: o desafio do século XXI. Rio de Janeiro: Garamond, 2010.

Desenvolvimento sustentável: que bicho é esse. Campinas, SP: Autores Associados, 2008.

VILLEY, Michel. En torno al contrato, La propiedad y La obligacion. Buenos Aires: Ediciones Ghersi, 1980.

. Formaçáo do Pensamento Jurídico Moderno. São Paulo: Martins Fontes, 2005.

WINCKLER, Silvana Terezinha; BALBINOTT, André Luiz. Direito Ambiental, Globalização e Desenvolvimento Sustentável. In: BARRAL, Weber; PIMENTEL, Luiz Otavio (Orgs.). Direito Ambiental e Desenvolvimento). Florianópolis: Fundação Boiteux, 2006. 